\title{
Electro-thermo-mechanical modelling and analysis of the Press Pack Diode in Power Electronics
}

\author{
P.Rajaguru ${ }^{1}$, H. Lu ${ }^{1}$, C. Bailey ${ }^{1}$, J. Ortiz-Gonzalez ${ }^{2}$, O. Alatise ${ }^{2}$ \\ ${ }^{1}$ Computational Mechanics Reliability Group, University of Greenwich, London, United Kingdom \\ ${ }^{2}$ School of Engineering, University of Warwick, Coventry, United Kingdom \\ Telephone: +44(0)2083318445, fax: +44(0)2083318665 and e-mail: p.r.rajaguru@gre.ac.uk
}

\begin{abstract}
This paper details a finite element modelling approach of the press pack assembly process for a diode in a power electronic module. Molybdenum and aluminum graphite have been investigated as suitable materials for the contact pad. Contact analysis has been used to model the pressurized thermal interface in order to extract both the stress and temperature distribution in the diode. Average temperature and von Mises stress on the chip for a combination of clamping pressure, load current and contact pad material have been extracted from the modeling results. At present, based on the assumptions and modeling parameters used, Aluminum Graphite seems to have better performance in comparison with molybdenum in terms of generating a lower average chip temperature. Additionally optimum clamping pressure has been estimated by performing a numerical optimisation analysis in order to minimise both the average temperature and stress in the chip.
\end{abstract}

\section{INTRODUCTION}

In this paper we present an electro-thermo-mechanical finite element modelling and analysis of a press pack single diode power electronic module (PPDPEM). The electrical and structural characteristics of the press pack offer certain advantages in some applications since most of the identified failure mechanisms are associated with bonded joints such as solder joints and wirebonds [1]. Eliminating both wirebonds and solder material helps minimise risk of fatigue failure and stress in the chip. The press pack (also named as flat pack in some literature) is assembled and mounted under pressure by specially designed force calibrated clamps [2]. In this study finite element modelling analysis has been conducted for a novel PPDPEM structure being assembled by a team from University of Warwick, UK. The structure is detailed in Figure 1.

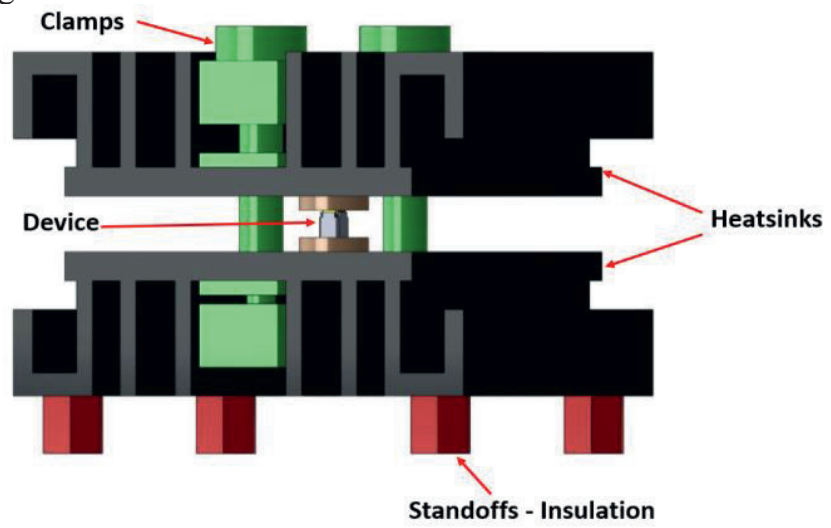

Figure 1: PPDPEM structure

The PPDPEM consists of an anode, anode pad, a single Schottky diode chip, cathode pad, and cathode layers. The anode and cathode materials are copper and the material of the pads are of either molybdenum (Mo) or aluminum graphite from Hoffmann Elektrokohle [3]. Aluminum graphite (AlG) a Metal Matrix Composite (MMC) produced by pressure infiltration of porous graphite by liquid aluminum. According to manufacturer specification, this new composite incorporates the advantageous properties of both materials. The type of AlG that was used in this study is $\mathrm{AlG}$ 2208. A CREE manufactured silicon carbide diode chip is used in the module. Enclosing the diode is a polypropylene sulfide (PPS) die carrier. The module is pressed by using a clamping kit and capsule device heatsinks. The module internal layers are pressed by the external force exerted by the clamping kit in order to form the appropriate electrical and thermal contact at the interfaces of the assembly as detailed in Figure 1 and 2.

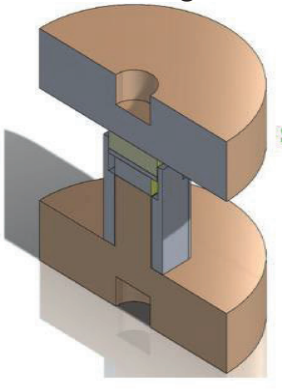

Fig 2: Press pack single diode device

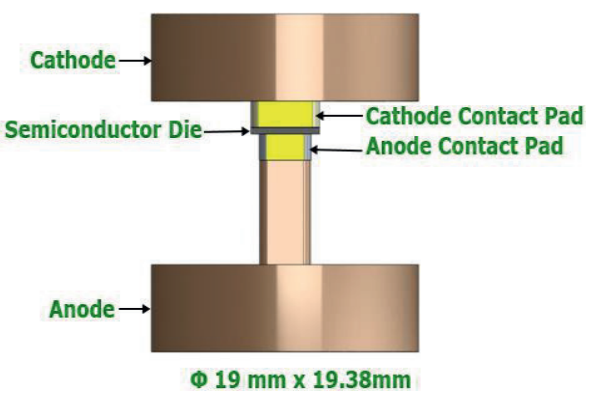

In contrast to fully bonded interfaces, press pack interfaces introduce additional electrical and thermal contact or constriction resistances due to interface surface roughness. This may result in higher electrical potential, which introduces higher temperature. However, fully bonded interfaces may result in higher thermo-mechanical stresses than press-pack interfaces due to the rigidity of the structure.

One of the key questions that arise with the press-pack process is how (1) contact pad material and (2) applied 
clamping pressure will affect both the junction temperature and stress on the $\mathrm{SiC}$ diode. This was the motivation behind the development of a finite element models and subsequent analysis. In this study, the clamping pressure varies between $300 \mathrm{~N}$ to $600 \mathrm{~N}$.

Another task of this study was to identify the optimum clamping pressure of the press pack for certain constraints.

Finite element analysis (FEA) as a modelling and analysis tool of press packs has been undertaken by many researchers. A FEA study on press pack insulated bipolar transistor (PPIGBT) was presented by Busca et al [4] for the impact of mechanical clamping pressure on the thermal distribution among the chips. Another thermo mechanical FEA study on PPIGBT was reported by Poller et al [5 and 6] who investigated the effect of external clamping pressure on the thermo mechanical behavior of an IGBT chip. A mechanical FEA study was presented by Hasmasan et al [7] for PPIGBT to calculate the clamping pressure distribution among chips for various clamping conditions. A similar study on PPIGBT was also reported by Pirondi et al [8 and 9]. An FEA study on PPDPEM as proposed in this study has not been reported in the literature.

In order to accurately model the electro-thermomechanical characteristics of the PPDPEM structure, the values of the electrical and thermal contact resistances between contact interfaces need to be known. However extracting the accurate contact resistances can be difficult since they are pressure sensitive. Measuring the contact resistances experimentally is infeasible as it is very difficult to place the measuring probe closer to the contact surface in small power electronic devices.

A number of approaches have been reported in the literature for predicting contact resistances. Poller et al [10] proposed a method to predict the electrical and thermal contact resistances by combining the finite element results with experiments. The experimental measurements were extracted from the surface of the IGBT chip of the press-pack assembly. Busca et al [11] predicted the thermal contact resistance of IGBT press-pack structure by combining experimental data with analytical calculations.

In this study we employed analytical models to estimate the contact resistances on the $\mathrm{Mo}$ (or $\mathrm{AlG}$ ) $/ \mathrm{Cu}$ and $\mathrm{Mo}$ (or $\mathrm{AlG} / \mathrm{SiC}$ interfaces. These analytical models are dependent on the external clamping pressure and contact material hardness. Additionally, the analytical model for the prediction of the thermal contact resistance also depends on the surface characteristics of contacting layers such as root mean square (RMS) of surface roughness and the mean absolute slope of the interface.

\section{FINITE ELEMENT MODELLING}

By exploiting symmetry in the module, one quarter symmetry has been assumed in the modeling study. The model consists of single chip and was developed in the ANSYS mechanical software. ANSYS is a powerful tool for its contact analysis capabilities. Complexity of the model structure for FEM simulation was further reduced by removing the heatsink in the model and its thermal effect is represented using an equivalent heat transfer coefficient.
According to the manufacturer's specification, the heatsink has a thermal resistance of $0.15{ }^{\circ} \mathrm{C} / \mathrm{W}$. In order to estimate the equivalent convection heat transfer coefficient of heatsink, we obtained the surface area of the heatsink from the specification. The thermal resistance and convection coefficient are related by the equation 1 is as follows [12]

$h_{\text {conv }}=\frac{1}{R_{\text {thha }} A}$

where $R_{\text {thha }}$, and $A$ are thermal resistance of the heatsink, and contact area of heatsink to the press package respectively. The equivalent convective heat transfer coefficient of the heatsink is approximated as $2437 \mathrm{~W} / \mathrm{m}^{2} \mathrm{~K}$ in this study.

The temperature dependent resistance of the diode chip was extracted from the forward current versus voltage plots for various temperatures from the manufacturer specification. For comparison purpose, bonded models where interfaces are fully bonded were also simulated. The electrical potential of the whole structure and junction temperature distributions of the diode chip from the press-pack simulations were compared with the fully bonded interface model simulations for a combination of mechanical pressure, electrical loading and two different contact pad materials. The press-pack model consists of four contact interfaces $(\mathrm{Cu} / \mathrm{Mo}$ (or $\mathrm{AlG}$ ), $\mathrm{Mo}$ (or $\mathrm{AlG}$ )/SiC, $\mathrm{SiC} / \mathrm{Mo}$ (or $\mathrm{AlG}$ ), and $\mathrm{Mo}$ (or $\mathrm{AlG}) / \mathrm{Cu}$ interfaces).

In ANSYS, surface to surface contact elements of CONTA174 and TARGE170 were utilised for the contact interfaces in the model. The volume of the structure was discretised using SOLID226 element which has electro thermo- mechanical capabilities. The model consisted of approximately 20,000 elements. Direct multi-physics coupling was performed for electric, thermal and mechanical analysis. The material properties used in this study are detailed in Table 1.

Table 1: Material properties of press package

\begin{tabular}{|c|c|c|c|c|c|}
\hline $\begin{array}{l}\text { Material } \\
\text { Property }\end{array}$ & Mo & AlG2208 & $\mathrm{Cu}$ & PPS & $\mathrm{SiC}$ \\
\hline $\begin{array}{c}\text { Density } \\
3 \\
\left(\mathrm{Kg} / \mathrm{m}^{2}\right)\end{array}$ & 10220 & 2300 & 8930 & 1350 & 3210 \\
\hline $\begin{array}{l}\text { Poisson } \\
\text { Ratio }\end{array}$ & 0.38 & $\begin{array}{l}\mathrm{x}, \mathrm{y}: 0.16 \\
\mathrm{z}: 0.2\end{array}$ & 0.343 & 0.3 & 0.14 \\
\hline $\begin{array}{l}\text { CTE } \\
\left(\mu \mathrm{m} / \mathrm{m}^{\circ} \mathrm{C}\right)\end{array}$ & 5.35 & $\begin{array}{l}\mathrm{x}, \mathrm{y}: 8 \\
\mathrm{z}: 12\end{array}$ & 16.4 & 49 & 4 \\
\hline $\begin{array}{l}\text { Young's } \\
\text { Modulus } \\
(\mathrm{GPa})\end{array}$ & 330 & 33 & 110 & 4.34 & 476 \\
\hline $\begin{array}{l}\text { Thermal } \\
\text { conductivity } \\
\left(\mathrm{W} / \mathrm{m}^{\circ} \mathrm{C}\right)\end{array}$ & 138 & $\begin{array}{l}\mathrm{x}, \mathrm{y}: 220 \\
\mathrm{z}: 140\end{array}$ & 385 & 0.255 & 370 \\
\hline $\begin{array}{l}\text { Specific } \\
\text { Heat } \\
(\mathrm{J} / \mathrm{Kg} / \mathrm{C})\end{array}$ & 217 & $800-950$ & 385 & - & 750 \\
\hline $\begin{array}{l}\text { Resistivity } \\
(\Omega / \mathrm{m})\end{array}$ & $5.3 e-8$ & $\begin{array}{l}x, y: 4 e-7 \\
z: 6 e-7\end{array}$ & $1.6 \mathrm{e}-8$ & $1 \mathrm{e} 14$ & - \\
\hline
\end{tabular}

\section{Thermal Contact Resistance}

Contact interfaces are never perfectly flat due to surface 
roughness. Thermal contact resistance depends on the surface, material hardness and contact pressure at the interface. Assuming negligible radiation heat transfer, the thermal contact resistance is given by equation 2 [13]

$$
h_{c}=0.125 k_{s} \frac{m}{\sigma}\left(\frac{P}{H}\right)^{0.95}
$$

where $k_{s}, \sigma, m, P, H$ are respectively the mean thermal conductivity, effective root mean square of surface roughness, mean absolute slope (flatness) of the interface, contact pressure of the joint and hardness of the softer material. If the mean absolute slope $(m)$ is not available, then mean absolute asperity slope $(m)$ can be approximated by the correlation equation 3 [14]

$$
m=0.125\left(\sigma \times 10^{6}\right)^{0.402}
$$

which is valid for a surface roughness range of $0.216 \mu \mathrm{m} \leq \sigma$ $\leq 9.6 \mu \mathrm{m}$.

\section{Electrical Contact Resistance}

Electrical contact resistance also depends on the contact force and the hardness of the contacting materials. When electrical current pass through the contact interface the current lines are restricted to pass through the reduced contacting area, this results in an increase in electrical resistance at the interface. Electrical contact resistance also named as 'constriction resistance' is approximated using the equation 4 [15 and 16]

$$
R_{\text {Elec_Con }}=\frac{\left(\rho_{1}+\rho_{2}\right)}{2} \sqrt{\frac{\pi H}{F}}
$$

where $\rho_{1}, \rho_{2}$, and $F$, are respectively electrical resistivity of the materials 1 and 2, and applied force on the contact joint. In this study, the hardness of the Mo and AlG were chosen as $1530 \mathrm{MPa}$ and $294 \mathrm{MPa}$ respectively [17].

\section{Boundary condition}

In the mechanical simulation the mechanical contact between contacting surfaces is controlled by friction. A friction coefficient of 0.75 was assumed between contact layers $\mathrm{Cu} / \mathrm{Mo}$ (or $\mathrm{AlG}$ ) and $\mathrm{Mo}$ (or $\mathrm{AlG}$ ) $/ \mathrm{Cu}$. Similarly friction coefficient of 0.5 is assumed for $\mathrm{SiC} / \mathrm{Mo}$ (or $\mathrm{AlG}$ ) interface [10]. Symmetry boundary conditions (displacement perpendicular to symmetry plane is zero and the rotational vector components parallel to the symmetry plane is also zero) imposed on the symmetry planes.

Clamping pressure varies for single diode package, hence a quarter of the original intended pressure applied on the cathode/heatsink interface and anode/heatsink interface has displacement constraint in out of plane direction. Electric current was applied to anode/heatsink interface by coupling the finite element mesh nodes and applying the current load to the master node.

\section{Simulation and Results}

The numerical simulation models with combined loading of current, clamping pressure and two different contact pad materials (Mo or AlG) have been simulated. Electrical and thermal contact resistances were dominated by the clamping pressure; for example, if clamping pressure increases, then the contact resistances decreases, but the stresses on the chip increases. The results from the simulation for von Mises stress, temperature and voltage distribution were extracted as in the Figures 3, 4 and 5.

From the numerical simulation, the average von Mises stress on chip and the average temperature on the chip were extracted by volume weighted averaging method which is widely reported in the literature.

$$
\sigma_{A v e}=\frac{\sum_{j} \sigma_{A v e}^{j} V_{j}}{\sum_{j} V_{j}}
$$

$V_{j}$ is the volume of one $j^{\text {th }}$ element and $\sigma_{A v e}^{j}$ is the associated von Mises stress.

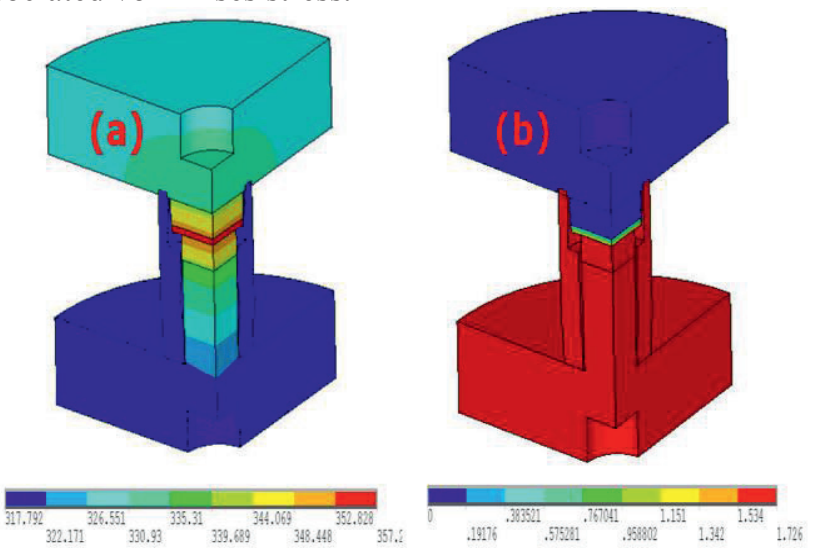

Fig 3: The numerical simulation with 20A input current, with AlG contact pad (a) Temperature distribution plot and (b) Voltage distribution plot

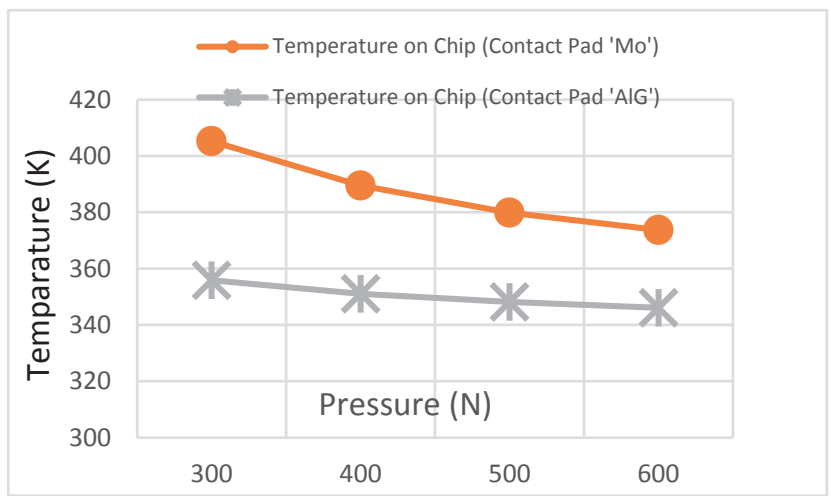

Fig 4: Average temperature plot on Diode chip versus clamping pressure for 20A Load current

Two quantities from the numerical simulation such as average temperature and average von Mises stress on the diode versus clamping pressure values are plotted in Figure 4 and 5. From the datasheet, the maximum junction temperature $\left(T_{j}\right)$ of diode is $175^{\circ} \mathrm{C}$. From Figure 4, the models with Mo contact pad generated higher average temperature in the diode chip in comparison with model with AlG contact pad for similar clamping pressure and load current. In contrast, the average von Mises stress is higher for model with AlG contact pad 
comparing with model with Mo pad as detailed in Figure 5. For both models the temperature decreases when pressure increases for $20 \mathrm{~A}$ load current. This trend was observed in various load current values as well. The values of von Mises stress on the diode chip differs by roughly $20 \mathrm{MPa}$ between Mo and AlG contact pads for 20A load current. By considering the temperature as the dominant factor, $\mathrm{AlG}$ seems to outperform the Mo as a contact pad material. This is what expected since the hardness value of $\mathrm{AlG}$ is low in comparison with Mo, hence small electrical and thermal contact resistances and consequently small average temperature on diode for model with AlG pad.

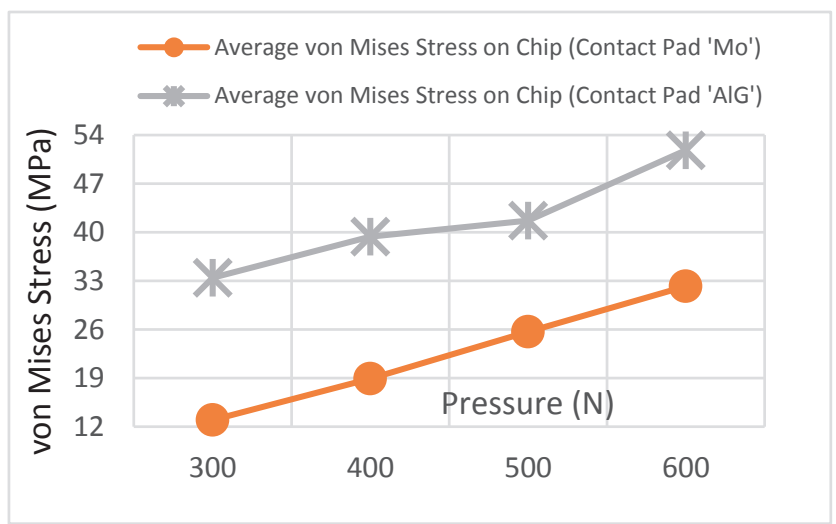

Fig 5: Average von Mises stress plot on Diode chip versus clamping pressure for 20A Load current

\section{THERMAL DISTRIBUTION ON DIODE}

The effect of contact pad material on the temperature distribution on the diode for various clamping pressures and load currents has also been investigated. The Fig 6 and 7 provide predicted temperature distributions on the diode chip for $400 \mathrm{~N}$ pressure loading. It can be concluded, that the maximum temperature difference of diode chip, between the model with Mo pad and the model with AlG pad, is decreasing as the clamping pressure increases. It is obvious that the model with Mo contact pad has the higher maximum temperature in comparison with the model with AlG contact pad for identical loading condition. Another observation is that an increment in load current value increases the temperature range in the temperature distribution for both cases as in the Tables (Table 2 and 3).

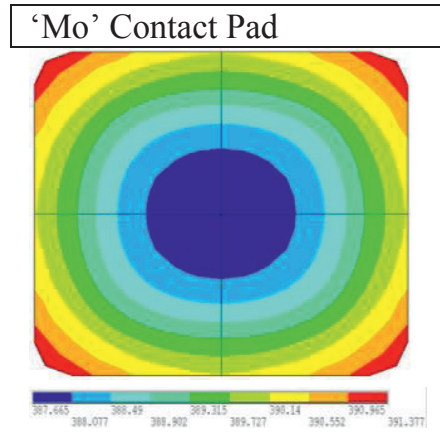

Fig 6: $20 \mathrm{~A}$ current, $400 \mathrm{~N}$ pressure, $\operatorname{Max}=391.4^{\circ} \mathrm{K}$, Min $=387.7^{\circ} \mathrm{K}$

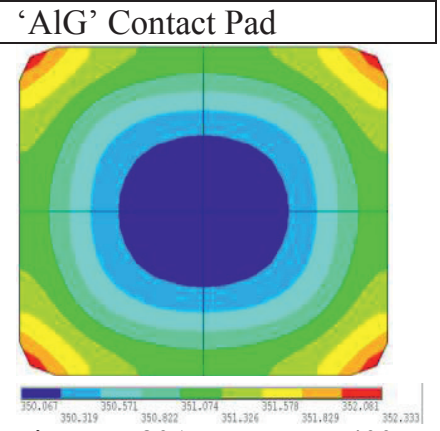

Fig 7: 20A current, $400 \mathrm{~N}$ pressure, $\operatorname{Max}=352.3^{\circ} \mathrm{K}$, Min $=350^{\circ} \mathrm{K}$
Table 2: Maximum temperature $\left({ }^{\circ} \mathrm{K}\right)$ on the diode chip for the model with 'Mo' contact pad

\begin{tabular}{|c|c|c|}
\hline Pressure (N) & & \\
\hline 400 & 20 & 25 \\
\hline 500 & 391.4 & 440.7 \\
\hline 600 & 381.7 & 424.8 \\
\hline
\end{tabular}

Table 3: Maximum temperature $\left({ }^{\circ} \mathrm{K}\right)$ on the diode chip for the model with 'AlG' contact pad

\begin{tabular}{|c|c|c|}
\hline Pressure (N) & & \\
\hline 400 & 20 & 25 \\
\hline 500 & 352.3 & 375.4 \\
\hline 600 & 349.4 & 370.6 \\
\hline
\end{tabular}

\section{OPTIMUM CLAMPING PRESSURE}

In this section a methodology for estimating the optimum clamping pressure is reported. At the optimal pressure, the temperature distribution and stresses on the diode are as low as possible for a constant load current. To achieve this a surrogate model has been developed and then used in numerical optimisation algorithms in order to identify the optimal clamping pressure. For a load current of $25 \mathrm{~A}$, the values of average temperature and average von Mises stress from the numerical simulation were extracted for various clamping pressure values, see Table 4.

Table 4: Average von Mises stress and temperature on the diode for 25A load current for various clamping pressure

\begin{tabular}{|l|l|l|l|l|l|}
\hline $\begin{array}{l}\text { Pressu } \\
\text { re (N) }\end{array}$ & $\begin{array}{l}\text { Norma } \\
\text { lised } \\
\text { Pressu } \\
\text { re }\end{array}$ & $\begin{array}{l}\text { Average } \\
\text { von Mises } \\
\text { Stress } \\
\text { (MPa) for } \\
\text { Mo } \\
\text { Contact } \\
\text { Pad }\end{array}$ & $\begin{array}{l}\text { Average } \\
\text { von } \\
\text { Mises } \\
\text { Stress } \\
\text { (MPa) } \\
\text { for AlG } \\
\text { Contact } \\
\text { Pad }\end{array}$ & $\begin{array}{l}\text { Average } \\
\text { Tempera } \\
\text { ture of } \\
\text { Diode } \\
\text { (K) for } \\
\text { Mo } \\
\text { Contact } \\
\text { Pad }\end{array}$ & $\begin{array}{l}\text { Average } \\
\text { Temper } \\
\text { ature of } \\
\text { Diode } \\
\text { (K) for } \\
\text { AlG } \\
\text { Contact } \\
\text { Pad }\end{array}$ \\
\hline 300 & -1 & 15.18 & 40.84 & 465.66 & 381.56 \\
\hline 400 & -0.333 & 19.47 & 46.07 & 437.61 & 373.68 \\
\hline 500 & 0.333 & 26.56 & 51.77 & 421.85 & 369.01 \\
\hline 600 & 1 & 33.83 & 51.74 & 410.40 & 365.70 \\
\hline
\end{tabular}

Wavelet Radial Basis Function (WRBF) Surrogate Model

A wavelet RBF (WRBF) neural network surrogate model with $n$ neurons has been used to interpolate the multidimensional $n$ sample data with zero error [18]. The interpolation is a method of predicting the new data points by 
forming of weighted average of the values at known surrounding points. The WRBF surrogate model is proposed as follows

$$
R(p)=a_{0}+a_{1} p+\sum_{i=0}^{4} \frac{b_{i}}{|\psi(0)|} \psi\left(A\left\|p-p_{i}\right\|\right)
$$

where $\Psi$ is the wavelet function, $A$ is the constant value chosen as 5 and $p$ is the normalized pressure value. Wavelet functions are widely applied in many fields because of their unique mathematical properties. The definition and the properties of the wavelet function are described by Charles [19]. Many wavelet functions are defined in the literature, in this study we utilised one of the widely known wavelets namely the Mexican hat wavelets [18] as in the Figure 8 is as follows.

$$
\psi_{\text {Mexicanhat }}(p)=\frac{2}{\sqrt{3}} \pi^{-1 / 4}\left(1-p^{2}\right) e^{-\frac{p^{2}}{2}}
$$

The coefficients of the surrogate models (Equation (5)) for average von Mises stress on chip for Mo pad $\left(R_{\text {Stess_Mo }}\right)$, for AlG pad $\left(R_{\text {Stress_AlG }}\right)$, average temperature on the chip for Mo contact pad $\left(R_{\text {Temp_MO }}^{-}\right)$, and for AlG contact pad $\left(R_{\text {Temp_AlG }}\right)$ are detailed in Table 5

Table 5: Coefficients of the WRBF surrogate models for four responses.

\begin{tabular}{|l|l|l|l|c|}
\hline Coefficient & RStess_Mo $_{\text {Stress_AlG }}$ & Remp_MO $_{\text {Temp_AIG }}$ & R $_{\text {Temp_a }}$ \\
\hline $\boldsymbol{a}_{\boldsymbol{0}}$ & 23.803 & 47.529 & 434.119 & 372.553 \\
\hline $\boldsymbol{a}_{\boldsymbol{1}}$ & 9.431 & 5.7 & -27.311 & -7.856 \\
\hline $\boldsymbol{b}_{1}$ & 0.82 & -0.884 & 4.214 & 1.142 \\
\hline $\boldsymbol{b}_{\boldsymbol{2}}$ & -1.093 & 0.24 & -5.036 & -1.332 \\
\hline $\boldsymbol{b}_{3}$ & -0.273 & 2.171 & -2.573 & -0.762 \\
\hline $\boldsymbol{b}_{4}$ & 0.546 & -1.527 & 3.394 & 0.952 \\
\hline
\end{tabular}

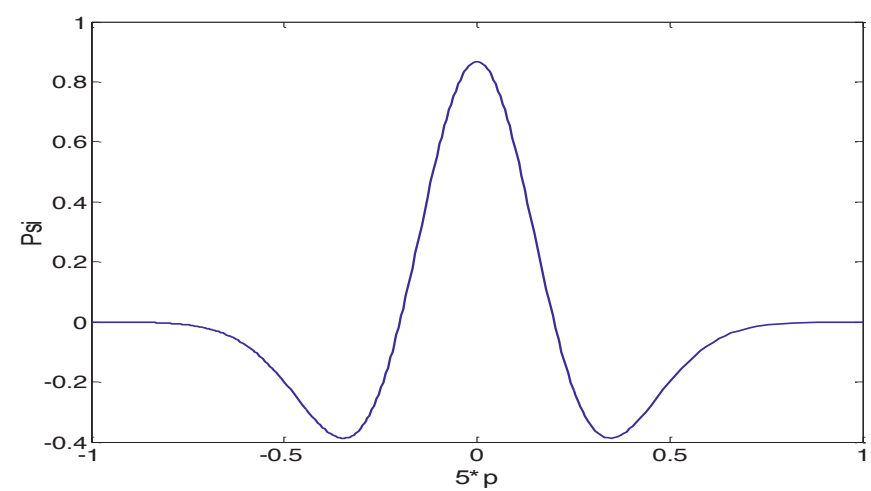

Fig 8: One dimensional Mexican hat wavelet in the range $[-1,1]$
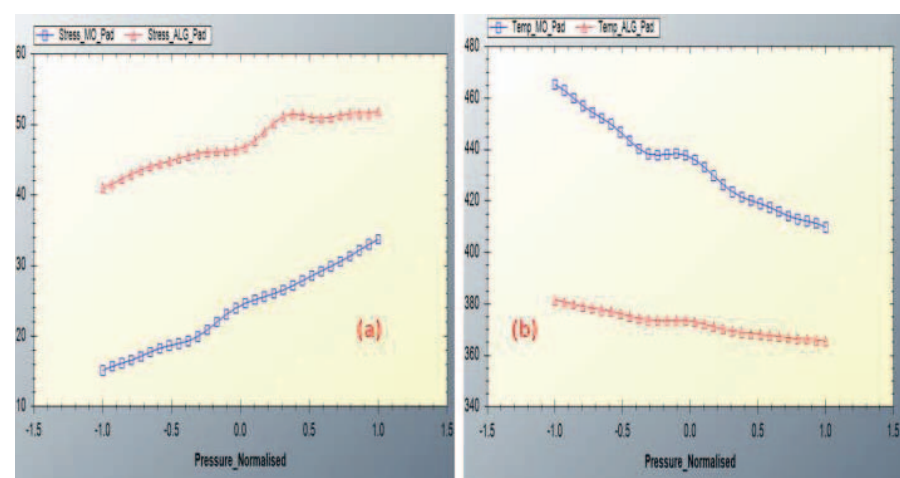

Fig 9: WRBF surrogate model plots for (a) average von Mises stress $(\mathrm{MPa})$ and $(\mathrm{b})$ average temperature $\left({ }^{\circ} \mathrm{K}\right)$ on diode

\section{Optimum Clamping Pressure}

The optimisation task was to evaluate the optimum pressure value at which average temperature and average von Mises Stress on the chip is minimised for constant load current and for a specific contact pad material. Since, the pressure is proportional to stress and inversely proportional to temperature, these are conflicting objectives. For both contact pad materials (AlG and Mo), a surrogate model representing the temperature and stress were minimised in order to estimate the optimum clamping pressure value.

Since this optimisation task is a multiobjective optimization, a single objective function was formed by taking a linear combination with positive coefficients of the both objective functions. This is also called a weighted sum method where the coefficients of the linear combination are called the weights. The weights for objective functions $\mathrm{R}_{\mathrm{Strss}}$, $\mathrm{R}_{\text {Temp }}$ were defined as 0.15 and 0.85 in this study. The above optimisation problems are defined and solved using the software package VisualDOC [20]. The optimisation task is solved using both gradient based algorithm and a global optimisation algorithm (particle swarm algorithm (PSO)). Within both techniques, PSO identified the same global optimal solutions (within the algorithm tolerances). The optimal results are listed in Table 6 . It was concluded that the optimum clamping pressure for model for both materials is roughly $400 \mathrm{~N}$.

Table 6: Optimisation results of the optimisation task.

\begin{tabular}{|l|l|l|}
\cline { 2 - 3 } \multicolumn{1}{c|}{} & $\begin{array}{l}\text { Sturcture } \\
\text { with 'Mo' } \\
\text { Contact Pad }\end{array}$ & $\begin{array}{l}\text { Structure } \\
\text { with 'AlG' } \\
\text { Contact Pad }\end{array}$ \\
\hline Rstrss (MPa) $_{\text {RTemp (K) }}$ & 19.357 & 45.866 \\
\hline $\begin{array}{l}\text { Normalised Optimum } \\
\text { Pressure }\end{array}$ & 438.688 & 373.749 \\
\hline Optimum Pressure (N) & -0.354 & -0.321 \\
\hline
\end{tabular}

\section{CONCLUSION}

In this study, we have presented a methodology which combines electro-thermo-mechanical finite element modeling predictions with numerical optimisation analysis for modeling and optimising a press pack diode in power 
electronic module (PPDPEM) structure.

In order to identify the superior contact material of the PPDPEM structure, a finite element analysis using the ANSYS software was conducted involving coupled multiphysics (electro-thermo-mechanical) analysis. The electrical and thermal contact resistances were estimated by using analytical models widely cited in the literature. Based on the assumptions used in this analysis, the current simulation results demonstrate that the structure with AlG contact pad has a lower temperature distribution on the diode chip in comparison with the model with Mo contact pad.

The optimization study has investigated optimum clamping pressure by using a surrogate model and a numerical optimisation algorithm for 25A constant load current. A surrogate model was generated by wavelet radial basis function interpolation for average stress and temperature on the chip for both contact pad materials. A multiobjective optimisation task was then undertaken using the Visual-Doc software tool. From this optimisation analysis it is currently concluded that $\sim 400 \mathrm{~N}$ is the optimum clamping pressure for both materials.

\section{ACKNOWLEDGMENT}

This research has been funded by the Engineering and Physical Science Research Council (EPSRC) through the Underpinning Power Electronics HUB (EP/K035304/1). It supports the cross theme project: Packaging with Operational Management and Control of Future High Current Press-Pack Silicon Carbide Modules

\section{REFERENCES}

[1] F.Wakeman, K. Billett, R. Irons, M. Evans, Electromechanical characteristics of bondless pressure contact IGBT, $14^{\text {th }}$ Annual Conference of Applied Power Electronic Conference and Exposition (APEC), Dallas, Texas, 1, pp 312 - 317, Mar 1999

[2] M. H. Rashid, Power electronics handbook, 3rd edition, Butterworth-Heinemann, 2011

[3] Hoffmann \& Co Elektrokohle AG, Aluminum Graphite Composites, http:/www.hoffmann.at

[4] A. A. Hasmasan, C. Busca, R. Teodorescu, L. Helle, F. Blaabjerg, Electro-thermo-mechanical analysis of high power press - pack insulated gate bipolar transistors under various mechanical clamping conditions, Institute of Electrical Engineers of Japan Journal of Industry Applications, 3(3), pp $192-197,2014$

[5] T. Poller, S. D'Arco, M. Hernes, A. R. Ardal, J. Lutz, Influence of the clamping pressure on the electrical, thermal and mechanical behavior of press - pack IGBTs, Microelectronics Reliability, 53, pp 1755 - 1759, 2013

[6] T. Poller, T. Basler, M. Hernes, S. D'Arco, J. Lutz, Mechanical analysis of press - pack IGBTs, Microelectronic Reliability, 52, pp 2397 - 2402, 2012

[7] A. Hasamasan, C. Busca, R. Teodorescu, L. Helle, Modelling the clamping force distribution among chips in press - pack IGBTs using the finite element method, 3rd IEEE International Symposium on Power Electronics for Distributed Generation Systems (PEDG), Aalborg, pp 788 - 793, June 2012

[8] A. Pirondi, G. Nicoletto, P. Cova, M. Pasqualetti, and M. Portesine, Thermo - mechanical finite element analysis in press - packed IGBT design, Microelectronics Reliability, 40, pp 1163, 1172, 2000
[9] A. Pirondi, G. Nicoletto, P. Cova, M. Pasqualetti, M. Portesine, P. E. Zani, Thermo-mechanical simulation of a multichip press-packed IGBT, Solid State Electronics, 42 (12), pp 2303-2307, 1998

[10] T. Poller, J. Lutz, S. D'Arco, and M. Hernes, Determination of thermal and electrical contact resistance in press-pack IGBTs, 15th European conference on Power Electronic and Applications, Lille, France, pp 1-9, Sep 2013

[11] C. Busca, R. Teodorescu, F. Blaabjerg, L. Helle, T. Abeyasekera, Dynamic thermal modelling and analysis of press - pack IGBTs both at component - level and chip level, 39th IEEE Conference of Industrial Electronics Society (IECON), Vienna, pp 677 - 682, Nov 2013

[12] Y. Cengel, Introduction to thermodynamics and heat transfer, McGraw Hill, 2008

[13] M. M. Yovanovich, Four decades of research on thermal contact, gap and joint resistance in microelectronics, IEEE Transactions on components and packaging technologies, 28(2), 2005

[14] V. W. Antonetti, T. D. Whittle, R. E. Simons, Approximate thermal contact conductance correlation, American society of mechanical engineers, Heat Transfer division, 170, pp $35-$ 42, 1991

[15] S. Ganesan, M. G. Pecht, Lead - free electronics, John Wiley \& sons, 2006

[16] P. G. Slade, Electrical contacts, principles and applications, 2nd edition, CRC Press, 2014

[17] J. F. Shackelford, and W. Alexander, Materials Science and Engineering Handbook, 3rd Edition, CRC Handbook, 2001

[18] H. Muzhou and H. Xuli, The multiresolution function approximation based on constructive wavelet RBF neural network, Applied soft computing, 11, pp 2173 - 2177, 2011

[19] K.C. Charles, An Introduction to Wavelets, Academic Press, Boston, 1994

[20] VisualDOC is a product of Vanderplaats Research \& Development Inc. (www.vrand.com/) 